\title{
O NOVO CÓDIGO DE PROCESSO CIVIL E O NÃO-JUIZ
}

\author{
Jorge Luiz Souto Maior ${ }^{1}$
}

\section{RESUMO}

O novo Código de Processo Civil regula os poderes, os deveres e a responsabilidade do juiz, deixando claro, desde o título, a inclinação do legislador para muito mais fiscalizar o juiz do que confiar em sua atuação. Aliás, pode-se dizer mesmo que a linha mestra do novo CPC é o aprisionamento do juiz, de modo a retira-lhe o poder jurisdicional e transformálo em gestor e reprodutor da lógica empresarial econômica.

PALAVRAS-CHAVE: NOVO CÓDIGO DE PROCESSO CIVIL. O PAPEL DO JUIZ. LIMITAÇÕES.

O novo Código de Processo Civil regula os poderes, os deveres e a responsabilidade do juiz, deixando claro, desde o título, a inclinação do legislador para muito mais fiscalizar o juiz do que confiar em sua atuação. Aliás, pode-se dizer mesmo que a linha mestra do novo CPC é o aprisionamento do juiz, de modo a retira-Ihe o poder jurisdicional e transformálo em gestor e reprodutor da lógica empresarial econômica.

A fórmula inscrita no novo CPC de circunscrever o princípio da dignidade humana ao critério da eficiência (art. $8^{\circ}$.), de extrair do juiz o julgamento por equidade, de vincular a prestação jurisdicional ao pedido, de procedimentalizar ao extremo a atuação do juiz, de transformar o juiz em gestor e de incentivar a atuação pautada pela reprodução de súmulas, além de não fazer qualquer menção ao papel do juiz frente aos princípios jurídicos e aos direitos humanos e fundamentais, representa um esvaziamento pleno da atuação jurisdicional.

O juiz, ademais, é um gestor que não inspira confiança nem mesmo para exercer a tarefa de administrar, pois o Código chega a dizer como o juiz deve organizar a sua pauta de audiências, e do qual, além disso, se requer uma atitude repressiva com relação aos servidores art. $233, \S 10$. Aliás, se nada funcionar já se tem no Código o veredicto: "culpado, o servidor".

\footnotetext{
${ }^{1}$ Graduado em Direito pela Faculdade de Direito Sul de Minas (1986), Mestrado (1995) e Doutorado (1997) em Direito pela Faculdade de Direito da Universidade de São Paulo. Pesquisa, em nível de pós-doutorado, realizada na França em 2001, financiada pela CAPES, sob orientação do Prof. Jean-Claude Javillier, professor da Universidade de Paris-II. Atualmente é professor livre docente da Universidade de São Paulo. Tem experiência na área de Direito, com ênfase em Direito do Trabalho, atuando principalmente nos seguintes temas: Direito do Trabalho, Teoria Geral do Direito do Trabalho, História do Direito do Trabalho, Direitos Humanos, Processo do Trabalho e Justiça do Trabalho.
} 
Interessante que o próprio novo CPC chega a reconhecer uma amplitude ao direito para além da lei, ao estipular que "O juiz não se exime de decidir sob a alegação de lacuna ou obscuridade do ordenamento jurídico" (art. 140), mas logo na sequência limita essa atuação ao julgamento com equidade, mas que estará autorizado somente "nos casos previstos em lei" (parágrafo único do mesmo artigo).

Claro que por via da interpretação se poderá dizer que a vinculação ao pedido está restrita às demandas de natureza privada, atingindo, pois, os efeitos de ordem pública, já que o artigo 141 assim dispõe: "O juiz decidirá o mérito nos limites propostos pelas partes, sendo-lhe vedado conhecer de questões não suscitadas a cujo respeito a lei exige iniciativa da parte." grifou-se. Ora, a contrario sensu, se poderia dizer que como para os efeitos de ordem pública a lei não exige iniciativa da parte, não haveria impedimento para que o juiz atribuísse tais efeitos para além dos pedidos formulados. No entanto, duvido muito de que esse alcance seja dado à referida norma.

No geral, o que se verifica é mesmo um incentivo para que o juiz não se proponha a interagir com a realidade social buscando corrigi-la e sim que elimine o processo, visto na lógica do conflito individual, dentro da maior previsibilidade possível.

Lembrando que o juiz está submetido ao cumprimento de metas e posto em comparação com outros juízes quanto aos números produzidos, o art. 322 constitui um forte elemento para impulsionar a atuação do juiz na lógica da disciplina judiciária, ainda que não se o fale expressamente.

Nos termos desse artigo, o juiz poderá julgar liminarmente improcedente o pedido, isto é, sem formalizar a lide, quando o pedido contrariar: "I enunciado de súmula do Supremo Tribunal Federal ou do Superior Tribunal de Justiça; II - acórdão proferido pelo Supremo Tribunal Federal ou pelo Superior Tribunal de Justiça em julgamento de recursos repetitivos; III - entendimento firmado em incidente de resolução de demandas repetitivas ou de assunção de competência; IV - enunciado de súmula de tribunal de justiça sobre direito local."

Com isso, aliás, dá-se mais peso jurídico à jurisprudência do que à própria lei, pois não há, no mesmo Código, e por certo não poderia mesmo 
haver, um efeito específico para quem formule uma pretensão que afronte a literalidade de uma lei, inquinando-a de inconstitucional.

Para satisfação de um julgamento célere, que satisfaz à lógica dos números, confere-se ao juiz, inclusive a possibilidade de "julgar liminarmente improcedente o pedido se verificar, desde logo, a ocorrência de decadência ou de prescrição" (§ $1^{\circ}$ do art. 322). Ou seja, permite-se ao juiz, que não pode julgar fora do pedido, segundo o Código, julgar fora do pedido do réu para julgar improcedente... Mas, afinal, para quê coerência se o objetivo de produzir números se satisfez não é mesmo?

E já que estamos no art. 322, qual a finalidade do disposto no $\S 20$ deste artigo? "Não interposta a apelação, o réu será intimado do trânsito em julgado da sentença, nos termos do art. 241." Como diria Renato Russo, "melhor nem comentar, mas a menina tinha tinta no cabelo".

Os artigos 489 a 495 constituem a sela do juiz, aprisionando-o exatamente no ato essencial da prestação jurisdicional, que é 0 do proferimento da sentença. O juiz, que pode quase tudo na fase instrutória, quando vai julgar deve seguir um padrão, um roteiro extremamente prolixo, que vai muito além do necessário para cumprir o papel básico da sentença, que é o de definir quem tem razão. De fato, o que resulta dos artigos em questão é a inviabilização prática da elaboração da sentença, sendo que o propósito disso é incentivar que o juiz se volte, com todo vigor, à atividade de conciliação ou punir o juiz que se arvore em ser juiz, forçando, na lógica da sobrevivência, a se submeter às súmulas.

Senão vejamos:

Art. 489. São elementos essenciais da sentença:

I - o relatório, que conterá os nomes das partes, a identificação do caso, com a suma do pedido e da contestação, e o registro das principais ocorrências havidas no andamento do processo;

II - os fundamentos, em que o juiz analisará as questões de fato e de direito;

III - o dispositivo, em que o juiz resolverá as questões principais que as partes Ihe submeterem.

$\S 1^{\circ}$ Não se considera fundamentada qualquer decisão judicial, seja ela interlocutória, sentença ou acórdão, que:

I - se limitar à indicação, à reprodução ou à paráfrase de ato normativo, sem explicar sua relação com a causa ou a questão decidida;

II - empregar conceitos jurídicos indeterminados, sem explicar o motivo concreto de sua incidência no caso; 
III - invocar motivos que se prestariam a justificar qualquer outra decisão;

IV - não enfrentar todos os argumentos deduzidos no processo capazes de, em tese, infirmar a conclusão adotada pelo julgador;

$V$ - se limitar a invocar precedente ou enunciado de súmula, sem identificar seus fundamentos determinantes nem demonstrar que 0 caso sob julgamento se ajusta àqueles fundamentos;

$\mathrm{VI}$ - deixar de seguir enunciado de súmula, jurisprudência ou precedente invocado pela parte, sem demonstrar a existência de distinção no caso em julgamento ou a superação do entendimento.

$\S 2^{\circ}$ No caso de colisão entre normas, o juiz deve justificar o objeto e os critérios gerais da ponderação efetuada, enunciando as razões que autorizam a interferência na norma afastada e as premissas fáticas que fundamentam a conclusão.

$\S 3^{\circ}$ A decisão judicial deve ser interpretada a partir da conjugação de todos os seus elementos e em conformidade com o princípio da boafé.

Art. 490. O juiz resolverá o mérito acolhendo ou rejeitando, no todo ou em parte, os pedidos formulados pelas partes.

Art. 491. Na ação relativa à obrigação de pagar quantia, ainda que formulado pedido genérico, a decisão definirá desde logo a extensão da obrigação, o índice de correção monetária, a taxa de juros, o termo inicial de ambos e a periodicidade da capitalização dos juros, se for o caso, salvo quando:

I - não for possível determinar, de modo definitivo, o montante devido; II - a apuração do valor devido depender da produção de prova de realização demorada ou excessivamente dispendiosa, assim reconhecida na sentença.

$\S 1^{\circ}$ Nos casos previstos neste artigo, seguir-se-á a apuração do valor devido por liquidação.

$\S 2^{\circ} \mathrm{O}$ disposto no caput também se aplica quando o acórdão alterar a sentença.

Art. 492. É vedado ao juiz proferir decisão de natureza diversa da pedida, bem como condenar a parte em quantidade superior ou em objeto diverso do que the foi demandado.

Parágrafo único. A decisão deve ser certa, ainda que resolva relação jurídica condicional.

Art. 493. Se, depois da propositura da ação, algum fato constitutivo, modificativo ou extintivo do direito influir no julgamento do mérito, caberá ao juiz tomá-lo em consideração, de ofício ou a requerimento da parte, no momento de proferir a decisão.

Parágrafo único. Se constatar de ofício o fato novo, o juiz ouvirá as partes sobre ele antes de decidir.

Art. 494. Publicada a sentença, o juiz só poderá alterá-la:

I - para corrigir-Ihe, de ofício ou a requerimento da parte, inexatidões materiais ou erros de cálculo;

II - por meio de embargos de declaração.

E vale reforçar: o artigo 489 é prática e logicamente inconcebível. Ora, se o juiz tiver mesmo que fazer todo esse exercício físico e mental para elaborar uma sentença, de 100 sentenças por mês passará a elaborar, no máximo, 10, desgastando-se, ainda, nos consequentes embargos, reclamações etc. No processo do trabalho o problema se potencializa porque quase todas as reclamações trabalhistas trazem uma acumulação bastante 
grande de pedidos, carregada, pois, de uma variedade enorme de questões jurídicas.

Com cerca de 3.500 processos novos a cada $\mathrm{ano}^{1}$, pressionado pelos números ditados pelas metas e pela concorrência, elaborar sentenças com todos esses elementos seria um autêntico martírio, o que, de fato, torna a sentença um ato irrealizável.

Verifique-se que a impossibilidade da elaboração da sentença não se trata unicamente de um problema quantitativo, mas também de uma decorrência extraída da lógica.

Ora, o Código estipula que a sentença não será considerada fundamentada se "deixar de seguir enunciado de súmula, jurisprudência ou precedente invocado pela parte", mas atribui o mesmo efeito se a sentença "se limitar a invocar precedente ou enunciado de súmula, sem identificar seus fundamentos determinantes". Assim, o juiz, segundo o Código, mesmo não com o conteúdo de uma súmula está obrigado a segui-la, mas não poderá se limitar a indicá-la, devendo, isto sim, trazer os fundamentos da súmula, mas esses fundamentos não estão de acordo com o seu convencimento, vendo-se, então, obrigado a apresentar os seus fundamentos e divergir deles para justificar a incidência da súmula, com a qual não concorda. Ou seja, uma coisa de doido!

A gravidade jurídica dos termos do artigo 489, no entanto, vai bem além disso, já que afronta a pedra fundamental do Estado Democrático de Direito e ordem jurídica internacional pautada pela prevalência dos Direitos Humanos, não tendo, portanto, eficácia concreta, como se esclarecerá mais adiante.

Mas vale insistir. O $\S 1^{\circ}$ do artigo 489 diz, textualmente, que "Não se considera fundamentada qualquer decisão judicial, seja ela interlocutória, sentença ou acórdão, que: (....) VI - deixar de seguir enunciado de súmula, jurisprudência ou precedente invocado pela parte, sem demonstrar a existência de distinção no caso em julgamento ou a superação do entendimento".

Ou seja, sentença que não segue enunciado de súmula, jurisprudência ou precedente invocado pela parte não é sentença. Mas então para que se

\footnotetext{
1 Dados do CNJ disponíveis em: http://www.cnj.jus.br/programas-e-acoes/pj-justica-emnumeros
} 
quer um juiz afinal? Não seria melhor um computador, efetuando-se coleta de dados e expressando o resultado pré-programado?

Sim, se dirá, mas o juiz pode não seguir enunciado de súmula, jurisprudência ou precedente invocado pela parte, mas somente se "demonstrar a existência de distinção no caso em julgamento ou a superação do entendimento", o que quer dizer que sendo o caso idêntico e ainda estando em vigor o entendimento da súmula qualquer coisa que dizer será tido como não dito!

Lógico que a criatividade não se consegue evitar e o juiz fará, quando queira, uma interpretação da própria súmula e uma desvinculação ao caso, mas isso só exigirá esforço que dificulta exatamente o objetivo da celeridade processual, alimentando incidentes e forçando, na lógica do contexto de restrição da atuação do juiz, a profusão de novas súmulas.

É bem verdade, também, que esse mal já havia sido integrado ao processo do trabalho por intermédio de uma lei que, de forma bastante curiosa, é uma espécie de anagrama da lei do novo CPC. Nos termos da Lei n. 13.015 de 2014, caberá a interposição de embargos no TST, quando as decisões das Turmas forem "contrárias a súmula ou orientação jurisprudencial do Tribunal Superior do Trabalho ou súmula vinculante do Supremo Tribunal Federal".

Dispõe, também, que:

O Ministro Relator denegará seguimento aos embargos: I - se a decisão recorrida estiver em consonância com súmula da jurisprudência do Tribunal Superior do Trabalho ou do Supremo Tribunal Federal, ou com iterativa, notória e atual jurisprudência do Tribunal Superior do Trabalho, cumprindo-Ihe indicá-la.

No caso de recurso de revista, interposto das decisões dos Tribunais Regional, a lei em questão adiciona a seguinte hipótese de admissibilidade quando as decisões "contrariarem súmula de jurisprudência uniforme" do TST ou súmula vinculante do Supremo Tribunal Federal.

Obriga, ainda, que Tribunais Regionais do Trabalho procedem a uniformização de sua jurisprudência, cumprindo-lhe aplicar, o incidente de 
uniformização de jurisprudência previsto nos termos do Capítulo I do Título IX do Livro I da Lei no 5.869, de 11 de janeiro de 1973 (Código de Processo Civil).

A lei em questão chega ao ponto de abrir a possibilidade de recurso de revista nas ações sujeitas ao procedimento sumaríssimo, o que até então não havia, "por contrariedade a súmula de jurisprudência uniforme do Tribunal Superior do Trabalho ou a súmula vinculante do Supremo Tribunal Federal e por violação direta da Constituição Federal" e passa a permitir a interposição de agravo de instrumento para "destrancar recurso de revista que se insurge contra decisão que contraria a jurisprudência uniforme do Tribunal Superior do Trabalho, consubstanciada nas suas súmulas ou em orientação jurisprudencial, não haverá obrigatoriedade de se efetuar 0 depósito referido no $\S 7^{\circ}$ deste artigo".

Adota o procedimento para julgamento de recursos repetitivos, que, instaurado, ensejará a suspensão, também nos regionais, de todos "os recursos interpostos em casos idênticos aos afetados como recursos repetitivos, até o pronunciamento definitivo do Tribunal Superior do Trabalho", sendo que "Publicado o acórdão do Tribunal Superior do Trabalho, os recursos de revista sobrestados na origem: I - terão seguimento denegado na hipótese de o acórdão recorrido coincidir com a orientação a respeito da matéria no Tribunal Superior do Trabalho; ou II - serão novamente examinados pelo Tribunal de origem na hipótese de o acórdão recorrido divergir da orientação do Tribunal Superior do Trabalho a respeito da matéria."

Por fim, no caso de revisão da decisão firmada em julgamento de recursos repetitivos, o que será possível:

\footnotetext{
quando se alterar a situação econômica, social ou jurídica", dispõe a lei que deverá ser "respeitada a segurança jurídica das relações firmadas sob a égide da decisão anterior, podendo o Tribunal Superior do Trabalho modular os efeitos da decisão que a tenha alterado.
}

Essa Lei, no entanto, não é um salvo-conduto para o novo CPC, significando apenas que o legislador está mesmo disposto a suprimir o poder jurisdicional dos juízes e nisto o novo CPC é, ao menos por ora, inigualável.

No âmbito dos tribunais dispõe o novo CPC que "Os tribunais devem uniformizar sua jurisprudência e mantê-la estável, íntegra e coerente" (art. 926), 
cumprindo-lhes editar "enunciados de súmula correspondentes a sua jurisprudência dominante" (§ $\left.1^{\circ}\right)$.

Complementa o artigo 927:

Os juízes e os tribunais observarão:

I - as decisões do Supremo Tribunal Federal em controle concentrado de constitucionalidade;

II - os enunciados de súmula vinculante;

III - os acórdãos em incidente de assunção de competência ou de resolução de demandas repetitivas e em julgamento de recursos extraordinário e especial repetitivos;

IV - os enunciados das súmulas do Supremo Tribunal Federal em matéria constitucional e do Superior Tribunal de Justiça em matéria infraconstitucional;

V - a orientação do plenário ou do órgão especial aos quais estiverem vinculados.

$\S 1^{\circ}$ Os juízes e os tribunais observarão o disposto no art. 10 e no art. 489, § $1^{\circ}$, quando decidirem com fundamento neste artigo.

$\S 2^{\circ}$ A alteração de tese jurídica adotada em enunciado de súmula ou em julgamento de casos repetitivos poderá ser precedida de audiências públicas e da participação de pessoas, órgãos ou entidades que possam contribuir para a rediscussão da tese.

$\S 3^{\circ} \mathrm{Na}$ hipótese de alteração de jurisprudência dominante do Supremo Tribunal Federal e dos tribunais superiores ou daquela oriunda de julgamento de casos repetitivos, pode haver modulação dos efeitos da alteração no interesse social e no da segurança jurídica.

$\S 4^{0} \mathrm{~A}$ modificação de enunciado de súmula, de jurisprudência pacificada ou de tese adotada em julgamento de casos repetitivos observará a necessidade de fundamentação adequada e específica, considerando os princípios da segurança jurídica, da proteção da confiança e da isonomia.

$\S 5^{\circ}$ Os tribunais darão publicidade a seus precedentes, organizandoos por questão jurídica decidida e divulgando-os, preferencialmente, na rede mundial de computadores.

Percebe-se, pois, que o aprisionamento jurisdicional se pretende também com relação aos desembargadores.

$\mathrm{Na}$ ânsia de auferir um resultado processual qualquer, sem interferência do magistrado, o artigo 932 chama a conciliação de "autocomposição", impondo ao relator do recurso a incumbência de homologá-la, como se não pudesse recusar o resultado atingido pelas partes, desprezando, pois, as implicações de ordem pública, que no processo do trabalho são muitas, como se sabe.

Nos termos do mesmo artigo, incumbirá também ao relator:

IV - negar provimento a recurso que for contrário a: a) súmula do Supremo Tribunal Federal, do Superior Tribunal de Justiça ou do 
próprio tribunal; b) acórdão proferido pelo Supremo Tribunal Federal ou pelo Superior Tribunal de Justiça em julgamento de recursos repetitivos; c) entendimento firmado em incidente de resolução de demandas repetitivas ou de assunção de competência.

E, ainda, "depois de facultada a apresentação de contrarrazões, dar provimento ao recurso se a decisão recorrida for contrária a: a) súmula do Supremo Tribunal Federal, do Superior Tribunal de Justiça ou do próprio tribunal; b) acórdão proferido pelo Supremo Tribunal Federal ou pelo Superior Tribunal de Justiça em julgamento de recursos repetitivos; c) entendimento firmado em incidente de resolução de demandas repetitivas ou de assunção de competência".

Para impedir que o juiz encontre meios de ser juiz, o novo CPC, então, se dispõe a regular o "incidente de assunção de competência", que é um eufemismo para o implemento de um expediente típico da ditadura, a avocação. Aqui, no entanto, não se fala em segurança nacional ou manutenção da ordem, mas em "relevante questão de direito, com grande repercussão social, sem repetição em múltiplos processos" (art. 947), como justificativa para excluir a construção coletiva da ordem jurídica por atuação dos juízes de primeiro grau, atribuindo tal tarefa a um "órgão especial", cujo entendimento "vinculará" a todos os juízes ( $\S 3^{\circ}$, art. 947).

Os artigos 948 a 950 regulam 0 incidente e arguição de inconstitucionalidade, quebrando a tradição brasileira do controle difuso da constitucionalidade, pelo qual os diversos juízes participam do processo democrático de construção da ordem jurídica.

E depois de superados todos os obstáculos procedimentais, chegandose ao trânsito em julgado da decisão de mérito, esta poderá ser rescindida quando "violar manifestamente norma jurídica", (inciso V, art. 966), o que pode levar à interpretação de que também as súmulas e jurisprudências dominantes estariam inseridas no conceito de norma jurídica, valendo lembrar que o dispositivo do CPC atual é bem menos amplo, já que se refere a "violar literal disposição de lei (art. 485, V, do CPC).

Explicitando ainda mais a preocupação central do novo CPC, que é a de vislumbrar a prestação jurisdicional como suporte para a racionalidade econômica, mesmo que a democracia e os direitos fundamentais, humanos e 
sociais sofram abalo, cria-se o "incidente de resolução de demandas repetitivas", como mecanismo de garantir "segurança jurídica" (art. 976, II).

É interessante perceber que existe aí de fato a preocupação em preservar o interesse do agressor da ordem jurídica. As alardeadas isonomia e segurança jurídica, proporcionadas pela adoção de um entendimento único para todos os casos, só interessam a quem se situa como réu em diversos processos, mas a esse o que se deve mesmo direcionar é a plena e total insegurança jurídica, pois está existe unicamente para quem cumpre regularmente a ordem jurídica.

Se a intenção fosse beneficiar as vítimas das agressões a direitos, 0 expediente, a exemplo do que prevê o Código de Defesa do Consumidor, só deveria gerar tais efeitos quando a decisão preservasse, com a maior potencialidade possível, o interesse do autor.

No fundo, trata-se, mais uma vez, de subtração do poder jurisdicional dos juízes de primeiro grau. Conforme dispõe o art. 985:

Julgado o incidente, a tese jurídica será aplicada:

I - a todos os processos individuais ou coletivos que versem sobre idêntica questão de direito e que tramitem na área de jurisdição do respectivo tribunal, inclusive àqueles que tramitem nos juizados especiais do respectivo Estado ou região;

II - aos casos futuros que versem idêntica questão de direito e que venham a tramitar no território de competência do tribunal, salvo revisão na forma do art. 986.

$\S 1^{\circ}$ Não observada a tese adotada no incidente, caberá reclamação.

E a situação está longe de favorecer a celeridade por conta da complexidade do procedimento adotado, embora preveja o prazo de um ano para o julgamento (art. 980), porque "Do julgamento do mérito do incidente caberá recurso extraordinário ou especial, conforme o caso" (art. 987) e o recurso "tem efeito suspensivo, presumindo-se a repercussão geral de questão constitucional eventualmente discutida" (§ $1^{\circ}$.).

Mas é claro que a questão uma vez chegada ao Supremo não se restringe ao seu próprio objeto. Aliás, vale destacar que nesses procedimentos não há nenhuma vinculação da prestação jurisdicional ao pedido das partes e aos balizamentos para julgamento. Os tribunais, e mais precisamente 0 Supremo e os Tribunais Superiores, podem tudo. Podem julgar além do pedido 
e podem apoiar suas decisões em quaisquer fundamentos e ainda imporem 0 resultado para qualquer cidadão, parte, ou não, de um processo, além, é claro, de limitarem a atuação dos demais juízes.

É nessa linha que o $§ 2^{\circ}$, do art. 987 arremata:

Apreciado o mérito do recurso, a tese jurídica adotada pelo Supremo Tribunal Federal ou pelo Superior Tribunal de Justiça será aplicada no território nacional a todos os processos individuais ou coletivos que versem sobre idêntica questão de direito.

Por fim, para garantir que nenhum juiz se rebele contra as diretrizes impostas, ou seja, se arvore em ser juiz, confere-se às partes e ao Ministério Público a possibilidade de apresentarem uma Reclamação, pode ser proposta perante qualquer tribunal (art. 988, $\S 1^{\circ}$.) , para:

I - preservar a competência do tribunal;

II - garantir a autoridade das decisões do tribunal;

III - garantir a observância de decisão do Supremo Tribunal Federal em controle concentrado de constitucionalidade;

IV - garantir a observância de enunciado de súmula vinculante e de precedente proferido em julgamento de casos repetitivos ou em incidente de assunção de competência. (art. 988)

O procedimento específico, como todos os demais, estabelece prazos, intervenção do Ministério Público e suspensão do processo. Na Reclamação, além disso, "Qualquer interessado poderá impugnar o pedido do reclamante" (art. 990).

E, novamente, a figura do julgamento fora dos limites do pedido e sem qualquer balizamento legal aparece:

Art. 992. Julgando procedente a reclamação, o tribunal cassará a decisão exorbitante de seu julgado ou determinará medida adequada à solução da controvérsia.

Art. 993. O presidente do tribunal determinará o imediato cumprimento da decisão, lavrando-se o acórdão posteriormente.

Também no reforço da atuação jurisdicional em consonância com súmulas e jurisprudências dominantes, destaque o art. 1.011, que permite ao relator, em recurso de apelação, decidir monocraticamente quando for se pronunciar em conformidade com o inciso IV e V, do art. 932, acima citado. 
Por fim, vale a referência ao art. 1022, que cuida dos embargos de declaração, os quais atingem, agora, qualquer decisão judicial, no sentido de que se considera omissa a decisão que:

I - deixe de se manifestar sobre tese firmada em julgamento de casos repetitivos ou em incidente de assunção de competência aplicável ao caso sob julgamento; II - incorra em qualquer das condutas descritas no art. $489, \S 1^{0 \prime}$.

Em suma, o novo Código de Processo Civil pretendeu criar a figura esdrúxula e atentatória ao Estado Democrático de Direito do "não-juiz".

\section{REFERÊNCIAS}

ARAGÃO, Egas Dirceu Moniz de. Sentença e Coisa Julgada. São Paulo: Aide, 1992.

BARBOSA, Rui. O Direito do Amazonas ao Acre Setentrional, 1910, vol.I. Rio de Janeiro: Editora Globo, 1920.

BERMAN, Marshall. Tudo que é sólido desmancha no ar, a aventura da modernidade. São Paulo: Companhia das Letras, 1986.

BORGES, Jorge Luís. História da Eternidade. Tradução de Heloísa Jahn, São Paulo: Cia. Das Letras, 2010.

BORJA, Célio. O Controle Jurisdicional de Constitucionalidade. In A Nova Ordem Constitucional. Rio de Janeiro: Editora Forense, 1990.

BUZAID, Alfredo. Da Ação Direta de Declaração de Inconstitucionalidade no Direito Brasileiro. São Paulo: Editora Saraiva, 1958.

DELGADO, José Augusto. Reflexões contemporâneas sobre a flexibilização, revisão e relativização da coisa julgada quando a sentença fere postulados e princípios explícitos e implícitos da Constituição Federal: manifestações doutrinárias. Disponível em: http://www.egov.ufsc.br/portal/sites/default/files/anexos/18540-185411-PB.pdf Acesso em 20/10/2012.

DIDIER JR, Fredie; DA CUNHA, Leonardo Carneiro. Curso de Direito Processual Civil. Volume 3, 10.ed., Salvador: Editora Jus PODIVM, 2012.

DINAMARCO, Cândido Rangel. Nova era do processo civil. São Paulo: Malheiros, 2003.

FULLER, Lon. The morality of law. New Harven, Yale University Press, 1969.

LEAL, Rosemiro Pereira. Teoria Geral do Processo. 11.ed. Rio de Janeiro: Forense, 2012. 
MARINONI, Luiz Guilherme. Coisa Julgada inconstitucional: a retroatividade da decisão (in) constitucional do STF sobre a coisa julgada; a questão da relativização da coisa julgada. 2.ed. São Paulo: Editora Revista dos Tribunais, 2010.

MEDINA, Teresa Alvim Wambier e José Miguel Garcia. O Dogma da Coisa Julgada. São Paulo: Editora Revista dos Tribunais, 2003.

MENDES, Gilmar Ferreira. Controle Concentrado de constitucionalidade. São Paulo: Editora Saraiva, 2001.

NASCIMENTO, Carlos Valder do. Coisa Julgada inconstitucional. 2.ed. Rio de janeiro: Editora América Jurídica, 2002.

NEVES, Celso. Coisa Julgada Cível. São Paulo: Editora RT, 1971.

OTERO, Paulo. "O ensaio sobre o caso julgado inconstitucional”, Lisboa: Lex, 1993.

ZAVASCKI, Teori Albino. Eficácia das Sentenças na Jurisdição Constitucional. São Paulo: Editora RT, 2001. 